\title{
Reconfigurable Weblabs Based on the IEEE1451 Std.
}

\author{
doi:10.3991/ijoe.v6i3.1277 \\ Ricardo Costa ${ }^{1,2}$, Gustavo Alves ${ }^{1}$, Mário Zenha-Rela ${ }^{2}$ \\ ${ }^{1}$ Polytechnic Institute of Porto, Porto, Portugal \\ ${ }^{2}$ University of Coimbra, Coimbra, Portugal
}

\begin{abstract}
Technology plays a double role in Education: it can act as a facilitator in the teaching/learning process and it can be the very subject of that process in Science \& Engineering courses. This is especially true when students perform laboratory activities where they interact with equipment and objects under experimentation. In this context, technology can also play a facilitator role if it allows students to perform experiments in a remote fashion, through the Internet, in a so-called weblab or remote laboratory. No doubt, the Internet has been revolutionizing the educational process in many aspects, and it can be stated that remote laboratories are just an angle of that on-going revolution. As any other educational tool or resource, the i) pedagogical approach and the ii) technology used in the development of a remote laboratory can dictate its general success or its ephemeral existence. By pedagogical approach we consider the way remote experiments address the process by which students acquire experimental skills and link experimental results to theoretical concepts. In respect to technology, we discuss different specification and implementation alternatives, to show the case where the adoption of a family of standards would positively contribute to a larger acceptance and utilization of remote laboratories, and also to a wider collaboration in their development.
\end{abstract}

Index Terms-E-learning, Remote experimentation, Remote laboratories, Reconfigurable weblabs, IEEE 1451.0 Std..

\section{INTRODUCTION}

The process of learning through technology is contributing to social changes. The size of available information for consulting has been imposing some pressure towards people, since they are now obliged to be constantly updated to avoid cultural and social isolation from the remaining society. Higher education has a big influence over this trend and must encompass current technological changes, so it may provide all means to satisfy people requirements by creating new educational resources. This has been happening since the 80's with the appearance of PCs and interactive CDs with multimedia contents. More recently, in current digital era, information circulates freely through internet and everyone have access to it, using PCs or mobile devices. This has been improving the learning process with the several educational tools developed, and technology is now viewed as fundamental to complement the traditional classroom. While at the beginning educational tools only covered traditional lectures, today the huge advances of internet services (larger bandwidth, many communication tools, etc.), have being promoting the adoption of learning technologies in the Sci- ences and Engineering (S\&E) courses, namely in the laboratorial work, through the so-called weblabs.

This paper starts with some considerations about the problems and the added value that technologies are bringing to education. Focusing in the S\&E courses, section III presents the relevance of experimental work, and section IV compares different laboratory environments. Section V describes the emergence and proliferation of weblabs, and the problems now faced by this educational technology. In this same section some infrastructural problems are pointed out and a reconfigurable weblab infrastructure, based on the IEEE1451 Std., is proposed.

\section{TECHNOLOGY IN EDUCATION}

In our present era, technology has been changing the way knowledge is acquired, facilitating students' access to information by lowering barriers once difficult to overcome due to social and economical restrictions. However, there are too many resources available, like books, journals, etc. that may contribute to information fragmentation, leading to an incoherent learning. This requires sense making to interpret, organize and link information to make it coherence. A critical attitude towards the learning process is fundamental, since not all the disseminated information is trustful (some are from specific entities, with credits in a specific area, and others are from individuals that can disseminate wrong information). A constructivist attitude is required, as students are building their knowledge based on information created by others.

Today skills are acquired not only inside a classroom but also outside, which requires an educational role based on two principles: i) traditional and ii) emergent. While traditional principles focus on pursuing ideals for influencing education to transform society with equality and democracy for all, following well defined theories and learning methods; emergent principles must defend a reaction of education to the technological trends, by adjusting theories and learning methods to influence students. This will be achieved by understanding students' needs and embracing their tools and skills, so it becomes possible to speak their languages and motivating them to learn, as already defended by theorists like Maslow or Herzberg's [1][2]. It is fundamental to look at education as a global process that may be improved through technologies. Spite the Social Development Theory presented by Vygotsky [3] focused on connections between people and the sociocultural context in which they act and interact by sharing experiences, it does not pay attention to a social context characterized by the existence of social networks, which provides even more interactions between people and 
internet-based resources. Here, the Communities of Practice (CoP) described by Jean Lave and Etienne Wenger in 1991 [4] is still actual, because technologies facilitate more interaction, allowing students' collaboration by sharing ideas, strategies and practical experiences, through a global network. They are able to acquire skills more easily than ever, and influencing their attitude towards learning. This has been promoting changes in higher education, by shifting its focus from knowing, described by epistemology as a conjunction of truths and believes, to being, described by ontology as capacities and processes that allow a student to get and easily understand new information. Students' curricula should emphasize qualities and attributes for learning, rather than particular knowledge elements. The much information available requires students' capabilities to learn by their own, so know-what can be supplemented by know-where information can be found.

The today's common Network Learning concept defines a process of developing and maintaining connections with people and information to support one another's learning. As described by Siemens and Tittenberger [5] this network comprehends several nodes divided in three levels: i) neural - based on neuroscience studies where nodes are neurons; ii) conceptual - related to cognition, the nodes are seen as ideas or collections of ideas; and iii) external/social - supported by new web technologies that allow interconnecting students by social networks, blogs, wikis, forums, etc.. At this level, a node is a person or an information resource. These led to the appearance of a new paradigm named Connectivism [6] that classifies each piece of information or student/teacher as a node that interconnected with others, understood and classified as relevant/irrelevant and trusty/untrusty will create knowledge, promoting a coherent learning, as illustrated in figure 1.

As all nodes are interconnected in a network, each may influence all the knowledge already acquired. A resistance for learning and the Cognitive Dissonance [7], which describes a discomfort feeling when new information appears and tends to change previous beliefs, are no longer relevant, since information is constantly changing and students must be well prepared for changing their ideas supported by a critical attitude. However, the diversity of technological solutions and the amount of information available, namely in the internet, may lead to confusion in students' research, requiring a critical attitude and teacher's guidance through the whole learning process.

As presented in figure 2, the educational landscape has been changing since the 80 's. If at the beginning the faceto-face instruction was the most preeminent method in education, the evolution of computers and the appearance of the internet, and its associated services and tools, incentivized students to learn (learning) instead of simple receiving information (instruction). Computers provided the use of simulations, interactive courses with multimedia contents, and other advanced resources, but the internet appearance brought the emergence of the e-learning concept providing the remote access to multimedia resources, the use of learning tools, the collaborative work using synchronous (e.g. videoconference) or asynchronous (e.g. e-mail) communication tools, etc.. Today, some of these tools are accessed through mobile devices (mobile phones, smart phones and PDAs) which provide the foundations of the m-learning concept. More recently appeared the web 2.0 allowing students and teachers to interact as a

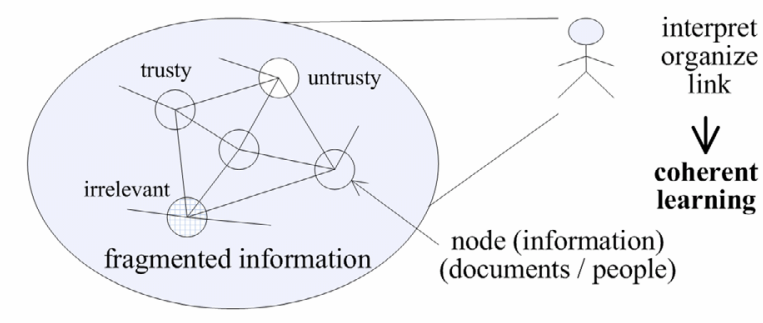

Figure 1. Coherent learning achieved through fragmented information.

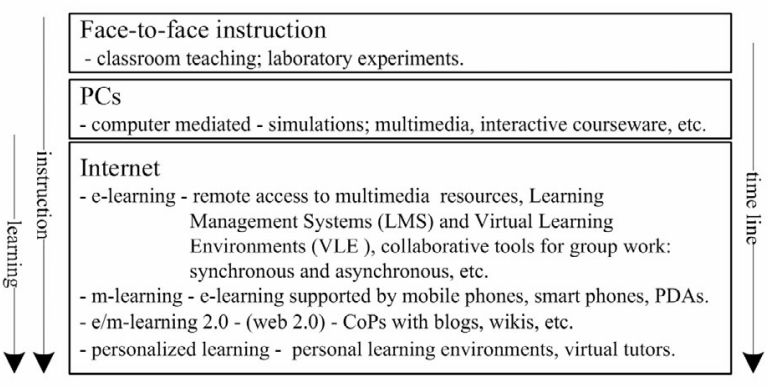

Figure 2. Educational landscape since the 80’s.

group (geographically dispersed) with web contents using blogs, wikis, etc., which allow to create and disseminate even more educational contents.

Since the educational context is becoming more personalized, the spread of different tools and contents in the internet may create some confusion in a student's mind. To overcome this aspect, Personal Learning Environments (PLE) are appearing to support students' creation of their own environment (supported by a set of tools) so they can control and manage their own learning process.

Applying technology in educational contexts promotes changes in the traditional in-classroom learning that can be i) extended, ii) partly replaced, or iii) entirely replaced by its application. Extending the classroom with technology resources is very common and has been applied through computers and multimedia resources for fostering what students learn in the traditional classroom. More recently, solutions ii) and iii) have been spreading in the educational context, since internet and its associated services fulfill basic requirements encountered in traditional classrooms:

dissemination - teachers/students can use websites and digital presentations with images and animations to disseminate their lectures/works, eventually supported by Virtual Learning Environments (VLEs), Learning Management Systems (LMS) and podcasts;

discussion - there are several communication tools available; from synchronous (chats, videoconference, etc.) to asynchronous (e-mail, discussion forums, blogs, etc.), all contributing for the required teacher-student and/or student-student interaction that facilitates cooperative and group work activities;

discovery - the internet provides access to several resources, allowing students and teachers to seek new information and tools;

laboratory work - using the so-called remote experimentation concept, students/teachers may run or demonstrate real laboratory activities through the internet; 
assessment - while self assessment can be made through current VLEs (which comprehend several tools), traditional classroom assessment can use synchronous communication tools, so teachers can control students' assessments.

In spite of the basic requirements fulfilled by technology, it is important to be aware of the sense of isolation that students may have if the in-classroom learning is entirely replaced by technology. Some literature points this aspect as a drawback to entirely adopt technology in educational contexts, because this may lead to students' frustration, decreasing their motivation. Moreover, currently educational trends in higher education defend the adoption of the Problem Based Learning (PBL) theory where students' tasks focus on solving specific problems proposed by teachers. The teachers' task is restricted to supervision and guidance of students, so they can solve problems by researching and making decisions by their own, which may cause some isolation. In this context, adopting a methodology partially supported by in-classroom learning and partially using online resources will facilitate the adoption of the PBL theory overcoming the isolation drawback. As defended by the Blended Learning concept, nowadays the learning processes tend to be hybrid or mixed focusing on technologies tendencies to partially replace the in-classroom learning, providing students and teachers with more resources to improve education. This aspect is being applied in S\&E courses, where the required experimental work is supported by educational tools.

\section{EXPERIMENTAL WORK}

To apply the PBL theory in higher education, technology resources, like internet and its associated services, are fundamental, since they facilitate students' research, giving them the opportunity to learn by their own. It is important to understand how the new educational tools can be adopted in the particular case of S\&E courses. As illustrated in figure 3, there are two important components for achieving learning: i) theoretical and ii) practical. While theoretical concerns transition of knowledge using the traditional pedagogical contents supported by documents, images and animations, describing specific theories; the practical component require students to be actively involved in the manipulation of variables and objects by doing experimental (or laboratory) work, researching, participating in group activities so they can understand, build, and verify theoretical concepts. In fact these are just some of the experimental skills that students should acquire in the laboratory environment, as reported by Feisel and Rosa in [8], which describes the role of the laboratory in engineering education.

Both theoretical and practical components are fundamental in every S\&E course, since almost every theory concerns practical issues, and vice-versa. Besides, applying PBL theory requires well designed courses dividing practical work into: i) resolution of exercises, ii) laboratory work (either traditional or simulated), iii) research, and, iv) group activities, among others. The results obtained through these activities, for acquiring a specific skill, will contribute for an autonomous learning process, since students are able to compare the results obtained in each activity, gathering variables to analyze a specific phenomenon. Supported by results, students can justify the validity of a specific problem, enriching the learned theories. If those variables do not correspond to the expectations provided by theories, students are invited to reformulate them. The relation between theoretical and practical work can be viewed as a cycle with two dependent components that, if applied, will promote more consistence, autonomy and responsibility in the learning process. Moreover, motivation increases, since students have the possibility to interact with the described phenomena in a learning-by-doing scenario. The teacher should guide students to choose specific literature and tools so they can satisfy both theoretical and practical components.

Each activity has differences that must be analyzed in terms of their importance in S\&E courses. While exercise solving and/or simulations provide results returned by theoretical models, i.e. students do not interact with real equipment; the traditional laboratory work gives students the possibility to work with real equipment where the results obtained can not be classified as non-real like in simulations or exercises.

Besides the importance of laboratory work for achieving good learning results, it is also fundamental to understand how students can be motivated to learn in S\&E courses. Reporting the educational theorist Kolb [9], students have four different styles for perceiving and processing new information: feeling and thinking (perception), and watching and doing (processing). The analysis made in [10] based on the preferred learning styles of $49 \mathrm{~S} \& \mathrm{E}$ students indicates that most preferred doing and thinking (which are typically of laboratory work) rather than feeling and watching, as illustrated in figure 4 . Moreover, the results obtained from a questionnaire made to those same students indicated laboratory work as the component that allows them to learn better, rather than lectures, reading or homework exercises.

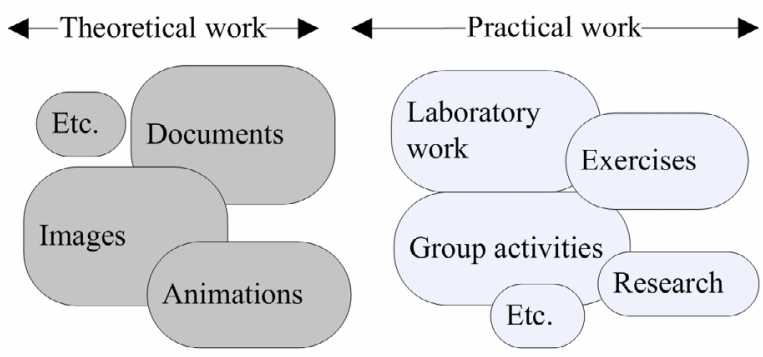

Figure 3. Theoretical and practical work.

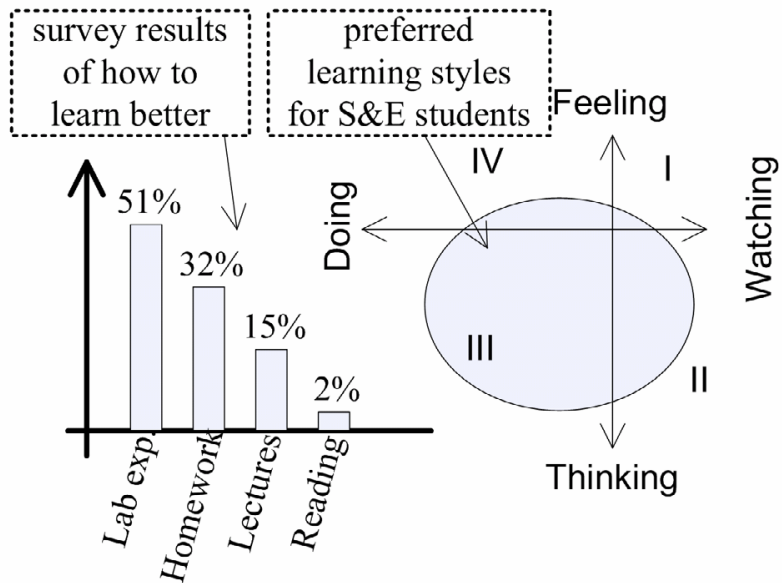

Figure 4. Survey results and preferred learning styles for learning in E\&S courses (reported from [10]). 
Supported by this analysis and reporting the research made by Ma and Nickerson [11], laboratory work is classified as one of the most important components of S\&E courses, since students are able to acquire experimental skills which are fundamental in a practice oriented field such as engineering. This has been motivating the analysis of how can laboratory work be enhanced through technology, namely by providing different laboratory environments.

\section{LABORATORY ENVIRONMENTS}

The proliferation of several technologies and services supported by internet allow creating several laboratory environments so students can conduct laboratory activities. As illustrated in figure 5, it is possible today to classify laboratories according to the access (remote or local) and resource (real or virtual) types, each one presenting specific characteristics:

Traditional laboratories - represent the common laboratory already available before the appearance of the internet and associated services. In these laboratories students have contact with several instruments/modules (I\&M) associated with an experiment and may or not may collect data through a computer. Student must physically be in the laboratory to conduct a specific experiment.

Remote laboratories - represent a remote access to real experiments, using an internet connection. Students interact with real equipment like in traditional laboratories, however they are not required to be in the laboratory, since they can access it through a simple device (mobile or not). All actions should be carried out using the accessing device.

Hybrid laboratories - these laboratory environments comprehend both kind of accesses and resources. Considering a remote access, students may use a simple device to access an experiment through the internet where, during the interaction with the I\&M associated with the experiment, some parts can be real and others can be simulated by software. If the access is local, the laboratory comprehends some real I\&M able to control locally like in traditional laboratories, but it has some simulated using a computer. Both are interconnected in the laboratory. This environment is still uncommon but it is important to consider it in occasions when the I\&M are expensive and/or unavailable, and in situations where experimental variables are impossible to visualize (e.g. visualization of magnetic field lines) [12][13]. By using these hybrid laboratories, students may collect data using their accessing devices or the computer that simulates a specific I\&M.

Virtual laboratories - all the I\&M are simulated using a computer. Although this solution comprehends the simulation of an experimental work, the interface provided for students must give them the sense that they are controlling real equipment. The access type can be either local or remote, as students can control a simulated laboratory by installing specific software on their devices or they can access a virtual laboratory through the internet. All data can be collected using the accessing device of each student.

The choice for a specific laboratory environment depends on educational contexts, comprehending the institutions, course requirements, and the type of students/ teachers that will use the laboratory. Hence, a detailed analysis based in some parameters and costs is required.

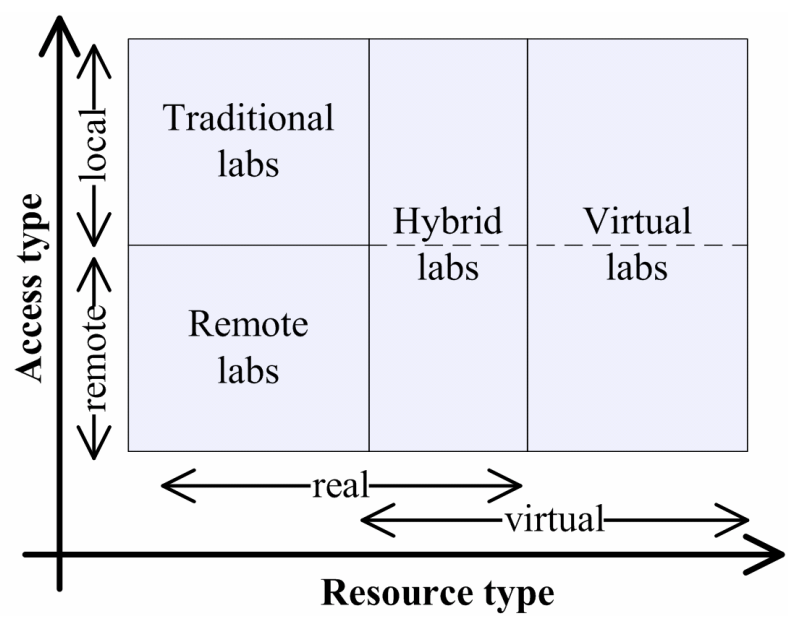

Figure 5. Types of laboratory enviroments.

The following parameters should be considered:

Availability - a specific experiment should be available at all time. Since typically there is a lack of infrastructures and I\&M to satisfy all students enrolled in a specific course, it is usual to schedule accesses, so experiments can be shared through time slots;

Reliability - it is fundamental to analyze theoretical approaches using reliable data retrieved from a specific experience, so theoretical approaches can be proved or reformulated. Moreover, reliability also concerns the stability of the implemented laboratory, namely if it is able to work correctly during long periods of time without setup requirements or maintenance;

Flexibility - the ideal laboratory environment should provide a platform (software and/or hardware) able to accommodate every kind of experiments, without changes;

Reusability - a specific laboratory or experiment should be able of being used more than once, and the I\&M should be able of being adopted/shared by other experiments available in the same institution.

Motivation - the provided experiments must be well designed to motivate students' adoption. The setup and reconfigurability must be easily defined by the student (preferably without teacher or technician assistance) and the interactivity and realism should be high, so students can have real time access to equipments and data;

Group activities - the ability to share experiences and ideas during laboratory work is fundamental to achieve good learning results. Hence, it is important to enable the conduction of experiments in groups, by allowing studentstudent and teacher-student communications. In an institutional level, sharing resources and I\&M will improve the value of the laboratory work, since each institution has its specific skills in different areas enabling more quality in the provided experiences. The sense of isolation and solitude, pointed as a drawback for learning, must be overcome by this interaction.

Costs can be divided into two groups: infrastructure /equipment, and those involving actors (students/teachers + technicians):

Infrastructure/equipment - if the local access is adopted, a laboratory experiment requires a physical space to accommodate both actors and equipment. If the remote access is adopted, an experiment does not require a large 
place for accommodation, since actors do not need to be in the laboratory place. Moreover, an analysis of the available equipment versus the cost of each unit together with the course requirements, in terms of how many laboratory experiments must be created, should be well analyzed. If the equipment is expensive and it is required several experiments, probably creating only one experiment able to share by several students is the best solution;

Actors - the setup and the maintenance of a specific laboratory require at least one technician paid by the institution. Although not directly related with the institution, if the local access type is adopted rather than a remote access, students may have associated dislocation costs.

Reporting to all these parameters, table 1 provides a comparison among laboratory environments. Each parameter was classified following our acquired experience in previous international projects (PEARL [14] or ReXNet [15]) and has a mark from 0 (less favorable) to 5 (more favorable). They were analyzed focusing the use of software or hardware and on network requirements to access a specific experiment. The particular case of motivation was classified based on the adoption of technology and on the use of real or virtual I\&M (i.e. higher motivation if students are using technology and real equipment).

TABLE I.

COMPARISON AMONG LABORATORY ENVIRONMENTS

\begin{tabular}{|c|c|c|c|c|c|c|c|c|c|c|}
\hline & \multicolumn{6}{|c|}{ Parameters } & \multicolumn{2}{|c|}{ Costs } & \multirow[b]{2}{*}{ 声 } & \multirow[b]{2}{*}{ 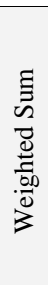 } \\
\hline & 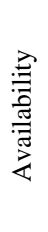 & 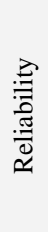 & 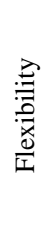 & 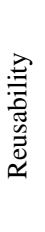 & 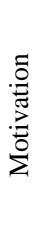 & 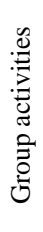 & 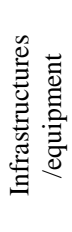 & 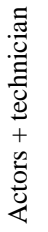 & & \\
\hline Traditional & 2 & 5 & 3 & 3 & 4 & 5 & 2 & 2 & 26 & 36 \\
\hline Remote & 3 & 4 & 3 & 4 & 5 & 4 & 4 & 5 & 32 & 40 \\
\hline $\begin{array}{l}\text { Hybrid } \\
\text { (remote) }\end{array}$ & 3 & 2 & 4 & 4 & 3 & 4 & 3 & 5 & 28 & 32 \\
\hline $\begin{array}{l}\text { Hybrid } \\
\text { (local) }\end{array}$ & 4 & 3 & 4 & 4 & 3 & 4 & 3 & 2 & 27 & 33 \\
\hline $\begin{array}{l}\text { Virtual } \\
\text { (remote) }\end{array}$ & 4 & 1 & 5 & 5 & 2 & 5 & 5 & 5 & 32 & 34 \\
\hline $\begin{array}{l}\text { Virtual } \\
\text { (local) }\end{array}$ & 5 & 2 & 4 & 4 & 2 & 5 & 5 & 2 & 29 & 33 \\
\hline
\end{tabular}

Summing all lines, we may observe that virtual (remote) and remote laboratories environments have the highest mark (32), and probably should be the preferred choices to conduct laboratory work. However, from our experience, reliable results should be the most important parameter of analysis. Hence, by giving at least 3 times more importance to the reliability factor, the results will change, placing remote and traditional laboratories on top, with 40 and 36, respectively. This is inline with several theories that defend laboratory work environments should be provided by both solutions, placing remote laboratories as a complement for traditional laboratories, because both return reliable results.

While traditional laboratory environments are applied in education since the beginning, today, with the internet proliferation and the associated services, remote laboratory environments are becoming widely adopted. So, the use of these environments conduct to the appearance of weblabs that are becoming widely adopted in S\&E courses.

\section{WEBLABS}

Weblabs are an important resource for complementing e-learning environments, as they provide the possibility to run remote experiments. Typically, weblabs are supported by VLE /LMS (e.g. Moodle) that provide all the pedagogical contents and resources that partly replace the traditional in-classroom activities. Remote experiments are accessible through simple 2D interfaces, and more recently, the use of 3D interfaces are being considered by the research community, since they provide an immersive environment where students can interact with the entire laboratory, approaching remote to traditional laboratory environments and increasing students' interest and motivation for laboratory work. Additionally, the recent technological evolution, which causes several instruments to be factory-equipped with Ethernet physical interfaces, is also promoting weblabs as important resources to improve laboratory work activities. This is proved by the increasing number of weblabs implemented at universities and schools [16] that give an added value to courses that usually only provide traditional laboratories, and to others courses that, due to a lack of resources (economical and/or technical), do not provide any laboratory work. This will facilitate changing the curriculum courses, giving students, spite of their social and economical conditions, access to real experiments and equipment, some expensive and others unavailable. There are no time constraints since students become more autonomous for conducting and repeating experiments at their own pace and they promote collaboration among different cultures and enable more "learn-by-doing”, increasing students' motivation [17]. However, the implementation of weblab infrastructures comprehends some problems, which, in our view, may be overcome by adding reconfigurable capabilities to them.

\section{A. Weblabs' problems and new reconfigurable weblabs}

Spite of the large variety of weblabs available today, a large majority is focused in engineering courses [11][18][19][20] mainly because technical skills are required to create a weblab infrastructure. Moreover, each infrastructure is typically developed following specific and distinct technical implementations, with several hardware and software architectures that use different programming languages to remotely control the equipment [16][21][22]. The lack of a standard solution is hampering the wide-spreading of weblabs since it creates some problems:

it does not promote large collaboration among institutions, because it is difficult to reuse and interface different instruments/modules used by a specific experiment;

some institutions do not develop weblabs for supporting their courses, because they lack the required technical skills;

costs may become high, since creating a weblab infrastructure requires a PC and associated software, together with several instruments;

an architecture based on a single PC, poses constraints for running different experiments, and the required software layers usually create actualization problems due to non-compatibility issues between versions.

To overcome these problems, the use of reconfigurable weblabs based on boards with Field Programmable Gate Arrays (FPGA) that support a wide range of peripherals 
(A/D and D/A converters, interface ports, etc.) is a good solution [23], since they allow the accommodation of several I\&M inside their memory blocks rather than using several independent instruments and a PC commonly adopted by traditional weblabs, as illustrated in figure 6 . Furthermore, developing those I\&M with open standard hardware description languages (VHDL/Verilog) and following a structure and an interface also defined by a standard, such as the IEEE 1451.0 Std., is a step in the direction of sharing and reusing the infrastructures and the I\&M on other experiences and by other institutions. The IEEE 1451.0 Std. is a valid option because it defines a set of open, common, network-independent communication interfaces [24].

The added value of a solution based on standards for developing a weblab is large, but requires further analysis accounting for its educational requirements.

\section{B. Added value of reconfigurable weblabs}

Reconfigurable weblabs are more robust than traditional ones, since they do not use several software layers. A simple reconfiguration file using VHDL/Verilog description languages is sufficient to implement different infrastructures. Furthermore, there are no actualization problems, since this kind of languages are independent of any other software and FPGA manufacturer.

As reconfigurable weblabs are developed using FPGAbased boards and the IEEE 1451.0 Std., their implementation costs are lower than traditional weblabs that use PCs and several instruments, some with specific features eventually not necessary for a specific experiment. Reconfigurable weblabs adopt the same platform to accommodate several I\&M able to be easily shared by several experiments that may (or may not) run in different institutions. Developing specific I\&M using hardware description languages, allows easily sharing them by a simple download process from a specific web server to reconfigure the FPGA-based board, as illustrated in figure 7. To remotely control/monitor each I\&M, a web interface should also be available. Hence, institutions may easily create their weblab without specific technical skills, since they become more reusable and flexible and the collaboration among institutions will increase, promoting the accomplishment of improved work group activities.

Providing access to a laboratory requires scheduling, so several students may share a specific experiment. While in traditional laboratory environments scheduling classes is common, for weblabs two solutions are commonly applied: i) booking systems [25] and ii) running experiments in batch mode [26]. From an educational perspective, weblabs should provide students' feeling that they are interacting with real equipment as they do in a traditional laboratory environment. So, typically booking systems allows students to reserve a time slot so they can have total control over the weblab, like in the traditional laboratory. The adoption of reconfigurable weblabs provides an improvement to the traditional weblabs in this availability aspect, since FPGAs can be reconfigured with different I\&M using two possible techniques: i) total reconfiguration or ii) partial (static/dynamic) reconfiguration. In total reconfiguration, using a new I\&M requires reconfiguring all the FPGA by stopping its operation. This may be an uninteresting option for experiments using many I\&M at the same time, since it requires stopping the weblab operation for changing them. Moreover, depending on the complex-

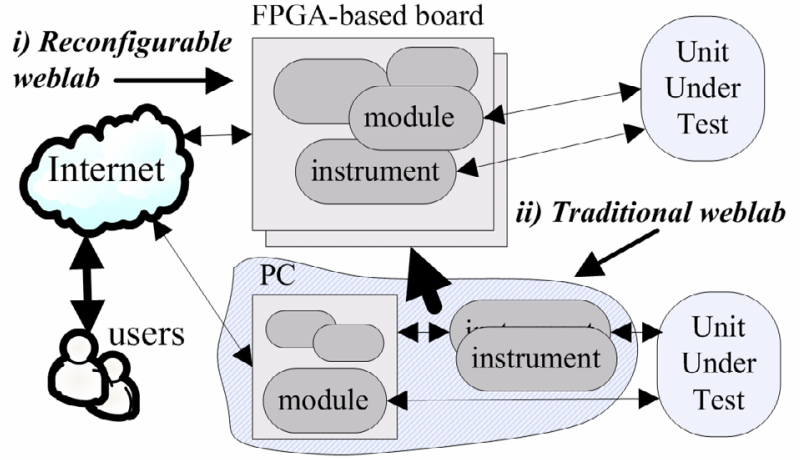

Figure 6. Traditional vs Reconfigurable weblabs architectures.

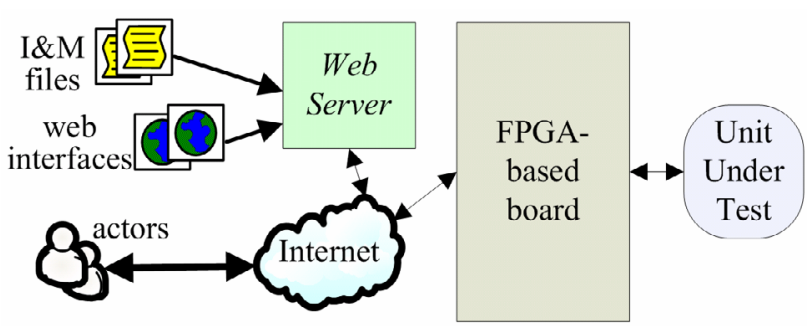

Figure 7. Distributed architecture proposed for FPGA-based weblabs.

ity of new I\&M and on current FPGA configuration, this option typically requires more time to reconfigure the weblab than the second one [27]. Therefore, option ii) may be more appropriated if one needs many I\&M to conduct an experiment, since it allows reconfiguring only part of the FPGA with one or more I\&M, without changing the others inside. Two alternatives are available for partial reconfiguration: a) static or b) dynamic. Static reconfiguration requires stopping the FPGA, while in dynamic reconfiguration an experiment may keep running even if an I\&M is changed. So, assuming one wants to change the reconfigurable weblab infrastructure when the logical space used inside the FPGA is totally occupied, only a fraction of it would be reconfigured, without affecting the rest of the FPGA. Eventually, that fraction could even be occupied by an I\&M in operation in that instant.

Following on the FPGA reconfigurable capabilities, figure 8 presents a solution to solve typical scheduling problems encountered in traditional weblabs when 1 to $\mathrm{N}$ students wish to conduct 1 to $\mathrm{N}$ experiments. When there is only one experiment for a single student, there are no scheduling problems. However, when a single experiment is available and several students want to access it, a scheduling access is required. As previously referred, a typical solution to solve this situation is the adoption of a booking system where students can reserve time slots. At that slot time, no one else can access the experiment, which can decrease the availability of the weblab. By adopting the proposed reconfigurable weblab, the FPGA reconfiguration techniques will solve this problem, because it is possible to reconfigure several I\&M, required for a specific experiment, in different FPGA's memory blocks. This allows student's transparent accesses to the experiments making them to believe that there are several available infrastructures. The only problem is the limited space available inside the FPGA that can also be solved using scheduling techniques or even the batch mode referred before. When one student wants to run different experiments, the reconfigurable infrastructure may pro- 


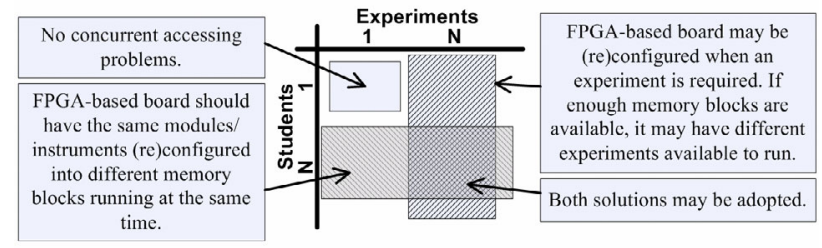

Figure 8. Solutions to run 1 to $\mathrm{N}$ experiments for 1 to $\mathrm{N}$ students on a single FPGA-based board.

vide different experiments running at the same time in different memory blocks or, in case of limited space, it is possible to change the experiments using one of the referred reconfiguration techniques. The most critical case appears if several students want to run different experiments. This requires the conjunction of both proposed solutions, i.e. the FPGA can be reconfigured with several experiments able to run at the same time for one specific student or, if several students want to run a specific experiment, it can be replicated in several memory blocks of the FPGA.

\section{Security issues}

The reconfiguration capability provided by the proposed weblabs may cause some problems if students have access to the entire weblab infrastructure. It is fundamental to control the actions they are able to do, to avoid damaging the infrastructure and problematic situations when dangerous experiments are available. This situation was already present in the traditional weblabs, because some infrastructures and experiments may also be damaged by student's interaction. To overcome this situation, the usual solution is to restrict student's access to specific actions over experiments, by limiting the functions available in the web interface.

In reconfigurable weblab, besides interacting with a specific experiment, students/teachers can also interact with the weblab infrastructure by changing I\&M. This freedom poses some security problems solvable through two alternatives: i) restrict the reconfiguration options of the laboratory to teacher and technicians; or ii) provide a web interface for each specific weblab infrastructure, limiting the reconfigurable options open to students. This last solution will decrease the weblab flexibility since it requires a specific interface for each infrastructure or experiment. Regardless of the adopted method, all I\&M should also be well tested and checked for compliance with the IEEE 1451.0, so not to damage the infrastructure. A solution is to have a unique trustful website integrating those modules such as the www.opencores.org website, or, in alternative, providing a tool able to check if those I\&M are in fact compliant with the standard.

\section{CONCLUSION}

Failing to observe a standard has hindered a larger collaboration between the academic fellows and institutions that have been developing and promoting the use of weblabs. Although there are some large consortiums (e.g. iLab, and VISIR, among others) that follow and share a common architecture in their weblabs, the adoption of a widely accepted and open accessible standard, like the IEEE 1451.0 std., would definitely contribute to a larger consensus around this educational technology, much in the same line of reasoning that led to the adoption elearning specifications like SCORM. If one regards we- blabs as a contributing educational tool (or resource) to elearning in S\&E courses, then quite reasonably the idea of adopting a collection of standards, such as the IEEE 1451 family of standards, for the development of sharable remote experiments, with permutable I\&M developed and made available by different institutions, will increasingly gain acceptance in the broad community devoted to Engineering Education. Besides the presented technological grounds, it is also important to evidence that the development of weblabs, namely their underlying infrastructure and I\&M, is, in itself, a didactical engineering activity for many graduating students. If, in a general development effort, one certain student develops a specific I\&M that can be easily downloaded and used by the entire weblabs' community then a real engineering development case will have been demonstrated to that particular student. Giving the large number of experiments done in the training phase of engineers (not mentioning their particular area, e.g. mechanics or chemistry, among others), then one can quickly foresee the huge potential for collaboration in the development and utilization of remote laboratories and experiments, if (and this should be clearly stressed) a universal standard is adopted. In our view, the IEEE 1451 std. is clearly an option in this direction, following the rational presented in this paper.

\section{ACKNOWLEDGMENTS}

This research work was financial supported by the IPPPolytechnic Institute of Porto (IPP) and the research laboratories CIETI-LABORIS/ISEP and CISUC/FCTUC. It is related with the undergoing $\mathrm{PhD}$ work of the first author, Ricardo Costa.

\section{REFERENCES}

[1] Maslow A. H., "A theory of human motivation,” Classics in Management Thought - Edward Elgar Publishing, vol. I, p.450, Issue 25, 1943.

[2] Herzberg F., "Work and the Nature of Man,” The World Publishing Company, Cleveland, $\mathrm{OH}, 1966$.

[3] Vygotsky L. S., "Mind in Society: Development of Higher Psychological Processes," Library of Congress Cataloging in Publication Data, 1978.

[4] Wenger E., "Communities of Practice -Learning, Meaning and Identity," Cambridge, England: Cambridge University Press, 1998.

[5] Siemens G. and Tittenberger P., "Handbook of Emerging Technologies for Learning,” http://www.umanitoba.ca/learning t echnologies/cetl/HETL.pdf, 2009.

[6] Siemens G., "Connectivism: A Learning Theory for the Digital Age,” http://www.itdl.org/Journal/Jan_05/article01.htm, 2005.

[7] Festinger L. and Carlsmith J. M., "Cognitive consequences of forced compliance,” Journal of Abnormal and Social Psychology, vol. 58, 1959.

[8] Lyle D. Feisel and Albert J. Rosa, “The Role of the Laboratory in Undergraduate Engineering Education,” Journal of Engineering Education, vol. 94, Jan. 2005, pp. 121-130.

[9] Kolb D. A., "Experiential Learning: Experience as the Source of Learning and Development,” Prentice Hall, Inc., 1984.

[10] Soysal, O. A, “Computer Integrated Experimentation in Electrical Engineering Education Over Distance,” ASEE 2000 Annual Conference, Saint Louis, MO,, Jun. 2000.

[11] Ma J. and Nickerson J.V., "Hands-on, simulated, and remote laboratories: A comparative literature review," ACM Computing Surveys, vol. 38, 2006, p. 7.

[12] Scheucher B. et al., "Collaborative Virtual 3D Environment for Internet-Accessible Physics Experiments,” International Journal of Online Engineering (iJOE), vol. 5, SI2, 2009. doi:10.3991/ijoe.v5s1.1014 
[13] Müller D. et al., "Mixed Reality Learning Spaces for Collaborative Experimentation: A Challenge for Engineering Education and Training," International Journal of Online Engineering (iJOE), vol. 3, 2007.

[14] Ferreira J. et al., "Collaborative Learning in a Web-accessible Workbench," Proceedings of the 8th International Workshop on Groupware (CRIWG'02), La Serena (Chile), Sep. 2002.

[15] Hine H. et al., "Institutional Factors Governing the Deployment of Remote Experiments: Lessons from the REXNET Project,” International Conference on Remote Engineering \& Virtual Instrumentation (REV'07), Porto. 2007.

[16] Gravier C. et al., "State of the Art About Remote Laboratories Paradigms - Foundations of Ongoing Mutations," International Journal of Online Engineering (iJOE), vol. 4, 2008.

[17] Barbara Means et al., Evaluation of Evidence-Based Practices in Online Learning A Meta-Analysis and Review of Online Learning Studies, EDUCASE: 2009.

[18] Massachusetts Institute of Technology, "iLabs: Internet access to real labs,” http://icampus.mit.edu/iLabs/, 2009.

[19] University of Deusto, "WebLab-Deusto,” https://www.weblab. deusto.es/, 2009.

[20] Faculdade de Engenharia da Universidade do Porto, "eLabs FEUP,” http://elabs.fe.up.pt/, 2009.

[21] Mergl C., "Comparison of Remote Labs in Different Technologies,” International Journal of Online Engineering (iJOE), vol. 2, 2006.

[22] Zubia J.G. et al., "Towards a canonical software architecture for multi-device WebLabs,” Industrial Electronics Society IECON 2005. 31st Annual Conference of IEEE, 2005.

[23] Costa R. et al., "FPGA-based Weblab Infrastructures - Guidelines and a prototype implementation example," 3rd IEEE International Conference on e-Learning in Industrial Electronics (ICELIE'2009), 3th to 7th Nov., Porto-Portugal, 2009, 2009.

[24] "IEEE 1451.0 Std. - Standard for a Smart Transducer Interface for Sensors and Actuators - Common Functions, Communication Pro- tocols, and Transducer Electronic Data Sheet (TEDS) Formats,” The Institute of Electrical and Electronics Engineers, Inc., 2007.

[25] Yaoye Li et al., “A scheduling system for shared online laboratory resources," 38th ASEE/IEEE Frontiers in Education Conference, 2008.

[26] Fujii N., "Work in progress -a dual mode remote laboratory system supporting both real-time and batch controls by making use of virtual machines," 38th ASEE/IEEE Frontiers in Education Conference, 2008.

[27] Gericota M. et al., "Run-Time Management of Logic Resources on Reconfigurable Systems," Proceedings of the Design, Automation and Test in Europe 2003 Conference and Exhibition (DATE'2003), 2003.

\section{AUTHORS}

Ricardo Costa is with the Department of Electrical Engineering (DEE) in the Polytechnic Institute of Porto School of Engineering (ISEP) and is attending a $\mathrm{PhD}$ course at the Department of Informatics Engineering (DEI) at the Faculty of Sciences and Technology in the University of Coimbra (FCTUC) (rjc@isep.ipp.pt).

Gustavo Alves is with the Department of Electrical Engineering (DEE) in the Polytechnic Institute of Porto School of Engineering (ISEP) (gca@isep.ipp.pt).

Mário Zenha-Rela is with the Department of Informatics Engineering (DEI) at the Faculty of Sciences and Technology in the University of Coimbra (FCTUC) (mzrela@dei.uc.pt).

This article was modified from a presentation at the IEEE EDUCON2010 conference Madrid, Spain, April 2010. Submitted March $19^{\text {th }}$, 2010. Published as resubmitted by the authors July $13^{\text {th }}, 2010$. 